\title{
Recursos constructivos en un soneto de Góngora
}

\author{
RICARDO SENABRE \\ Dpto. de Lengua Española \\ Universidad de Salamanca
}

\section{RESUMEN}

Las páginas que siguen muestran la armazón constructiva del soneto gongorino "La dulce boca que a gustar convidan, por la cual su autor se distancia del soneto de Torquato Tasso, que le ha servido de modelo. Se trata de una técnica basada en estructuras duales que comportan una secuencia temporal, con un antes y un después, una fase de deslumbramiento y el posterior desengaño, como conviene al propósito admonitorio de esta composición.

Palabras clave: Poesía, Góngora, Siglo de Oro.

\section{SUMMARY}

The author discusses the framework upon which Gongora's sonnet "La dulce boca que a gustar convidan is built, by which the poet departs from his model, a sonnet by Torcuato Tasso. Gongora's technique of using dual structures implies a sequence in time, a before and an after, astonishment followed by disappointment, as befits the admonishing aim of this type of composition.

Key words: Poetry, Góngora, Spanish Golden Age.

El soneto de Góngora "La dulce boca que a gustar convida", fechado por los estudiosos hacia 1584 -es decir, en la época juvenil del poeta-, ha despertado la atención de algunos comentaristas, si bien sus acercamientos al texto se han visto condicionados por las semejanzas visibles que existen entre el soneto gongorino y otro de Torquato Tasso - apuntadas ya por Salcedo Coronel, como se encargó de recordar Millé (1972)—, lo que ha llevado a adoptar enfoques comparatistas que permitieran dilucidar la dependencia de un texto respecto al otro y el grado de originalidad del poeta cordobés (Rossi 1961; Doddis 1961; Gross 1962), cuestión que ya Millé parecía haber dejado establecida al anotar con resolución, siguiendo a Salcedo Coronel: "Traducción libre $-\mathrm{y}$ verdaderamente superior a su

RDTP, LX, 1 (2005): 99-107 
modelo- de un soneto de Torcuato Tasso" (Millé 1972: 1139). Estos planteamientos, sin duda muy enriquecedores, han dejado un tanto al margen, sin embargo, aspectos relativos a la propia configuración del soneto como estructura verbal, importantes porque nos sitúan en una época de aprendizaje del autor, que había comenzado dos años antes a ensayar el modelo estrófico de los catorce versos endecasílabos en el que pronto sería maestro indiscutible. Pues bien: la armazón constructiva del soneto, lo que contribuye de manera decisiva a distanciarlo de sus modelos, constituirá el objeto de estas notas. Al fin y al cabo, el aprovechamiento de materiales procedentes de Torquato Tasso - muchos de los cuales, a su vez, se derivan de otros autores - forma parte del procedimiento imitativo característico de la estética renacentista (Ulivi 1959; Darst 1985; García Galiano 1992), y, por consiguiente, la originalidad atribuible al producto artístico no reside tanto en sus componentes aislados como en su peculiar combinación. Recordemos, antes de nada, el texto del soneto gongorino, que reproduzco según la edición de B. Ciplijauskaité (1968: 128), con tan sólo algunos leves retoques en la puntuación:

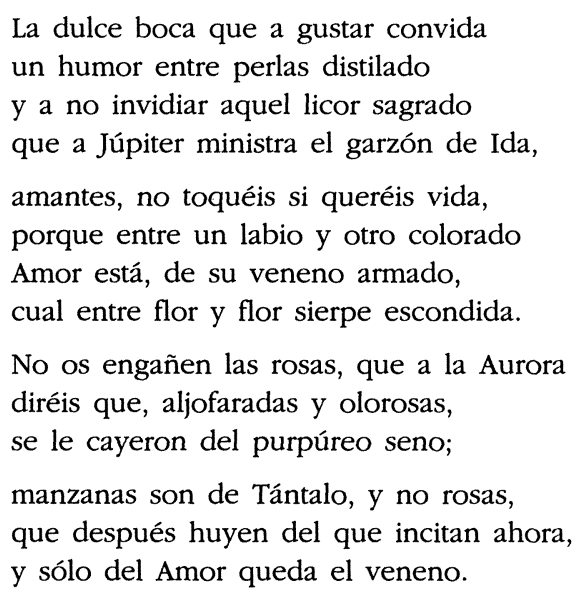

El propósito del soneto es claramente admonitorio: con una característica actitud barroca, se trata de advertir acerca del engaño de los sentidos. La apariencia de las cosas es únicamente una capa superficial que oculta la verdadera realidad. Este contraste entre el parecer y el ser, entre el mundo que vemos y el auténtico, induce a la desconfianza, motivo que acabará siendo esencial en el desarrollo pleno del pensamiento barroco y de sus manifestaciones artísticas -Quevedo o Gracián ofrecerán incontables muestras de esta postura-, pero que ya se encuentra aquí prefigurado con maestría, como se verá inmediatamente. Porque aquí el engaño con- 
tra el que se previene, la apariencia que oculta una realidad de signo muy diferente, es la belleza femenina y la atracción del amor, acaso el motivo temático más frecuente en la lírica de todos los tiempos. La advertencia a los "amantes" se presenta como necesaria porque los casos ejemplares de ofuscación y los infinitos empeños ciegos que han conducido a muchos enamorados al infortunio y a la desdicha ofrecen abundantísimos ejemplos, no ya en la vida, sino - lo que resulta aquí fundamental, puesto que es el espacio propio del soneto como construcción artística - en la literatura.

La idea inicial comporta ciertas exigencias constructivas. Por un lado, el contraste entre apariencia y realidad, entre lo que vemos y lo que luego descubrimos tras la superficie parece tener su cauce de expresión idóneo en estructuras duales. Si creemos ver una cosa y luego resulta ser otra, no sólo hay dos estratos diferentes, sino que, además, establecen una secuencia temporal, con un antes y un después, una fase de deslumbramiento y un descubrimiento posterior, como en cualquier proceso de engaño y desengaño. Por otra parte, si la apariencia nos ciega y nos arrastra hasta el punto de no dejarnos ver lo que oculta es porque posee un atractivo fascinante. He aquí, por tanto, algunos principios constructivos que parecen imponerse desde el primer momento: la justificación del deslumbramiento, el carácter marcadamente binario del proceso y su estratificación temporal. Veamos de qué modo estos factores condicionan la construcción estrófica y, a la vez, reciben gracias a esta disposición un realce sobresaliente.

La atracción amorosa se centra en el atractivo de la «boca", convertida en representación arquetípica de la más soberana belleza. Es necesario, pues, hermosearla, magnificar sus cualidades, convertirla en algo único e irresistible. Éste es el cometido del primer cuarteto, que se encarga de potenciar la mencionada "boca" mediante artificios retóricos reconocibles por cualquier aficionado de la época como procedimientos de realce. El más simple es de naturaleza sintáctica: la anteposición del adjetivo. "Dulce boca" es, frente a la construcción posible «boca dulce», una fórmula más artificiosa y encarecedora, debido precisamente a la profusión de un uso literario que ha ayudado a sentirla como tal. Una simple ojeada a la poesía de Garcilaso proporciona innumerables ejemplos de anteposición, como "áspera mudanza", "errado proceso", "dulces prendas", "hermosas ninfas", "dulce fruto", "hermosa cumbre", "dulce son" y muchos otros casos análogos. Si se repasa la égloga I, los resultados son parecidos y, además, el adjetivo "dulce" no parece conocer otra posición que la adelantada, sobre todo cuando su significado nada tiene que ver con el sabor: "dulce lamentar", "dulce primavera", "dulce habla", "dulce sueño", "dulce nido", "dulce garganta", "dulce prenda". 
El segundo procedimiento embellecedor es la hipérbole metafórica: la boca contiene "un humor entre perlas distilado". De nuevo recurre Góngora deliberadamente a una imagen frecuentadísima en la poesía anterior y fácilmente reconocible como artificio artístico: la que hace de "perla" una variante literaria -exclusivamente literaria- de 'diente'. El uso metafórico se combina con un símil que introduce en el texto otro factor de magnificación: el paradigma prestigioso que proporciona la mitología clásica y que se recuerda, de acuerdo con la deixis utilizada, como algo consabido, perteneciente al código de convenciones que gobierna la poesía ("aquel licor"). El "humor" de la boca se equipara al néctar que Ganimedes - -el garzón de Idam - sirve a Júpiter. El símil se ve reforzado, además, por la elección de las palabras nucleares, cuya homofonía parcial es evidente: el "humor" de la boca es asimilable al "licor" que bebe el dios de los dioses. Conviene subrayar que nada de esto aparece en el soneto de Tasso, cuyo primer cuarteto dice así:

Quel labbro che le rose han colorito molle si sporge e tumidetto in fuore, spinto per arte, mi cred'io, d'amore a fare a' baci insidioso invito.

El propósito de Góngora es, en efecto, presentar una boca absolutamente perfecta, con todos los atributos imaginables de la hermosura física, lo que justificaría la irresistible atracción ejercida sobre los "amantes" a quienes se dirige la admonición, imantados por la fascinación de la belleza inigualable. En el texto, esta idea de perfección sin máculas se traduce en la cuidadosa construcción del enunciado que cubre el cuarteto inicial, donde incluso las rimas son algo más que recursos fónicos y mnemónicos. Si se observan con detenimiento los versos se advertirá que la rima en -ida está presente en la noción de 'convidar a beber' ("que a gustar convida") con que comienza el soneto, y, cuando se repite en el verso cuarto, vuelve a introducirnos en la misma noción, ya que "el garzón de Ida" es precisamente el copero de Júpiter y le suministra la bebi$\mathrm{da}$, como el propio Góngora recordará de nuevo en las Soledades (I, 7-8: "...Cuando el que ministrar podia la copa / a Júpiter mejor que el garzón de Ida....). La rima en -ida se convierte de este modo en una especie de representación fónica de la noción 'beber, degustar' y subraya, por tanto, la proximidad semántica entre los versos que relaciona. En cambio, la rima en -ado que gobierna los versos centrales del cuarteto se asocia a una idea distinta, que ya no es la acción de beber sino el líquido que se bebe. La vecindad entre el "humor [...] distilado" del segundo verso y el ulicor sagrado" del tercero muestra con claridad que la rima establece re- 
laciones más profundas que las que se reducen al plano fónico, y ayuda, en consecuencia, a fortalecer la espesa red de conexiones y correspondencias textuales que constituye el entramado del cuarteto.

Con todo, aún es preciso plantear una cuestión que afecta al conjunto de estos cuatro versos: su función sintáctica dentro de la primera parte del soneto. Al comenzar la lectura $\multimap$, con mayor precisión, al escuchar los versos, que para eso fueron compuestos-, el transcurso de cuatro endecasílabos con sus correspondientes pausas crea una inusitada expectación, porque nada indica qué se va a predicar de esa "boca" que parece presentarse como sujeto del enunciado. Todo lo que hay a partir de su mención, ya desde el primer verso, es una prolongada expansión sintáctica formada por dos segmentos coordinados ("que a gustar convida [...] y a no invidiar"), cada uno con su propio desarrollo, que aplazan la información esperada: ¿qué pretende el sujeto lírico decir, a fin de cuentas, acerca de la "dulce boca?" Hay que esperar hasta la conclusión del cuarteto de endecasílabos con toda su complejidad sintáctica para encontrar el predicado, ya en el segundo cuarteto: "no toquéis". Y súbitamente advertimos que el inesperado imperativo nos obliga a volver atrás y a rectificar nuestra primera impresión, porque convierte lo que habíamos creído sujeto del enunciado en complemento. "La dulce boca" y todas las expansiones que arrastra a lo largo del cuarteto constituyen, dicho con la terminología tradicional, el complemento directo del predicado "no toquéis". Pero tal ordenación es insólita. Claro está que existen posibilidades en la sintaxis española de anteponer el complemento directo, pero ocurre tan sólo en algunos casos de construcciones sintagmáticas breves que suelen exigir, además, algún refuerzo pronominal (el jardín lo regué ayer", "a los niños los llevan en autobús", etc.). En el soneto de Góngora, la colocación anticipada de un complemento tan extenso es absolutamente excepcional, incluso con relación a la obra del autor compuesta en esos años, y casi nos sitúa en el umbral de los audaces hipérbatos que el poeta utilizará con impar maestría en las grandes creaciones de su madurez. Pero lo que cuenta en este momento es entender por qué consideró Góngora que la disposición invertida del enunciado, con un extenso complemento anticipado que rompía el orden gramatical esperable, era la solución más adecuada para prevenir contra los engaños de la apariencia. La explicación tiene que ver con el ya señalado planteamiento binario del tema que el soneto desarrolla y que establece dos fases, dos estratos temporales en el proceso que se trata de evocar: el engaño primero va seguido de un desengaño posterior; la apariencia hermosa descubre luego, oculta tras ella, una realidad muy distinta. Por eso, reproduciendo la secuencia cronológica, el primer cuarteto está dedicado a la magnificación de la hermosura per- 
fecta, que atrae y deslumbra, y el segundo —que, por serlo, aparece más tarde en la secuencia de la lectura o la audición- refleja la verdad descubierta más tarde, el desolador desengaño que muestra la esencial falsedad del mundo y la debilidad de nuestros sentidos. Porque el segundo cuarteto pulveriza implacablemente, en efecto, el encanto despertado por el anterior, y lo hace acudiendo a los mismos recursos realzadores - la hipérbole y la comparación prestigiosa - que el cuarteto inicial:

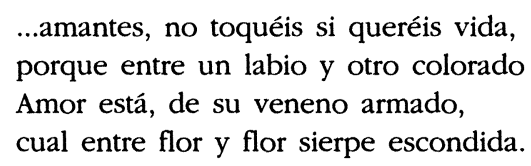

Después de las ponderaciones que llenaban el primer cuarteto, la advertencia "no toquéis" y la grave amenaza "si queréis vida" constituyen un giro tan brusco que requiere inmediata explicación; de ahí la construcción causal que preside los versos 6-8. Ahora, la "boca" del cuarteto inicial está vista de otro modo: "un labio y otro [labio]". El objeto único se ha dividido en dos porque, imaginativamente, la "dulce boca" ha comenzado un movimiento de apertura. Acaso puede sorprender la concordancia en singular de "colorado". El soneto pertenece a una época en que estos casos son vacilantes, aunque la tendencia general parece inclinarse a la concordancia en singular cuando los sujetos son del mismo género. El Lazarillo escribe "sin uno y otro padre" o "la verdad y bondad suya", y Valdés "la pronunciación y escritura arábiga" en el Diálogo de la lengua. El propio Góngora, en un soneto de 1621, ofrece una visión y una construcción similares, en dos versos portentosos que, tres siglos más tarde, aún resonarán en otros del libro Retornos de lo vivo lejano, de Rafael Alberti, al evocar uese mínimo espacio que media entre dos bocas / antes de reducirse a un clavel silencioso". La acuñación de Góngora dice: "Las hojas del clavel, que había juntado / el silencio en un labio y otro bello". Como es notorio, la formulación se halla muy cerca de la que ofrece el soneto "La dulce boca que a gustar convida". Pero existe también la concordancia en plural, que comienza a aplicarse con sujetos de género distinto. "El entendimiento y memoria divertidos", escribe santa Teresa en el Libro de la vida. Y Hernán Cortés en una de sus Cartas: "Llevando mi delantera y recuaje bien concertados". Sea como fuere, los usos gongorinos parecen inclinarse hacia la concordancia en singular, al menos con sujetos del mismo género gramatical. A pesar de todo, el singular "colorado" aplicado al plural "un labio y otro" aporta, quizá sin intención alguna por parte del autor, un matiz preciso a la información: esos dos labios son la misma "boca" de antes - les conviene, pues, el atributo en singular-, que 
ahora se ha entreabierto en una implícita invitación al beso. La sutileza de la sugerencia aparta una vez más el texto de Góngora del soneto de Tasso, donde el motivo era palmariamente expuesto en el verso "a fare a' baci insidioso invito".

La boca entreabierta no sólo incita al beso, aumentando así la tentación y el peligro, sino que permite ver la lengua, móvil como una serpiente y, como ella, mortal. De nuevo surge el símil, como en el cuarteto primero, y el prestigio y la contundencia de la lección no se derivan aquí sólo de la tradición mitológica — presente en el recuerdo elusivo del "Amor" armado con dardos venenosos-, sino también de la literatura: la serpiente entre las flores recrea, como en otros lugares de Góngora (Gates 1933: 39-40; 1935: 50; Alonso 1955: 103), las palabras conocidas de Virgilio ("latet anguis in herba", Bucolica, III, 93), utilizadísimas en la poesía del Renacimiento de toda Europa hasta convertirse en un lugar común, que aquí cobra un significado suplementario al equipararse a la lengua que asoma entre los labios "como entre flor y flor". La expresión procede también de Tasso ("tra fiore e fiore"), pero en Góngora sirve para rematar una breve cadena progresiva de conceptos que ayudan a transmitir el proceso de apertura y la atracción irresistible: la "boca" del comienzo aparece luego como "labio y [labio]" para transmutarse posteriormente en "flor y flor", a medida que el imaginativo beso se completa. También este cuarteto aprovecha las rimas para reforzar semejanzas de sentido. La rima en -ida aparece en la amenaza de muerte del verso quinto ("no toquéis si queréis vida"), noción esencial para caracterizar la letal "sierpe escondida" del verso octavo, que revela de este modo su enlace con el anterior. En cuanto a los versos interiores del cuarteto, fuertemente trabados por la relación sintáctica, el "veneno" del verso sexto es la misma sustancia que contiene lo que hay "entre un labio y otro", como se decía en el endecasílabo anterior.

Los tercetos están construidos con técnica análoga a la utilizada en los cuartetos: el primero presenta los aspectos más gratos y deslumbrantes del objeto, si bien precedidos ya de la admonición "no os engañen", inevitable desde el momento en que se ha descubierto la realidad oculta bajo la apariencia atractiva. Las "rosas" son una nueva variante que completa la serie boca-labio y llabiol-flor y flor-rosas. De nuevo aparece el símil prestigioso en el recurso conjunto a la mitología y a la literatura. Salcedo Coronel señaló el precedente de Bernardo Tasso ("Queste purpuree rose, che a l'Aurora / al apparir del di cadder del seno...n), y también puede recordarse la recreación de Pedro Espinosa publicada en las Flores de poetas ilustres: “Estas purpúreas rosas que a la Aurora / se le cayeron hoy del blanco seno..." (Espinosa 1975: 18). Pero es un tópico frecuente. 
Giovanni Battista Strozzi, por ejemplo, había escrito (Lirici 1968: 276): "Dal cel cadeo gentil candida rosa / di grembo scorsa alla rosata Aurora...”. El mismo Góngora volvió a utilizarlo en un romance de 1621: “Caído se le ha un clavel / hoy a la Aurora del seno". Lo que cuenta una vez más es el uso deliberado de una fórmula literaturizada, fuertemente marcada por su pertenencia al ámbito poético, sólo para recalcar el carácter ficticio y artificial de la belleza engañosa. Las "rosas" o labios son ahora "aljofaradas". Como las rosas frescas del amanecer, cubiertas de minúsculas gotas de rocío, los labios aparecen húmedos. Se consuma de este modo uno de los besos más portentosos de la poesía española.

Y después de esta magnificación, el desengaño al presentar el flanco negativo de las cosas. La ilusión se desvanece con el descubrimiento de que las rosas eran más bien "manzanas" de Tántalo. En realidad, la tradición, desde Ovidio al De natura deorum de Boccaccio o la Philosophía secreta de Pérez de Moya, habla de frutas, sin especificar de qué clase. Es de Tasso de quien toma Góngora la conversión de la genérica fruta en manzanas, todavía con formulación de símil: "Quasi pome di Tantalo, le rose / fansi al incontro e si allontanan poì. La tradición mitológica sufre aquí la interferencia - resuelta en afortunado sincretismo- de la tradición cristiana, donde la manzana representa, desde el Génesis, el paradigma de la tentación femenina, y tiene, por consiguiente, un lugar privilegiado en el planteamiento y los motivos del soneto. La composición camina hacia su desenlace y recobra, con un sentido preciso de la simetría estructural, algunas de las marcas constructivas que la han presidido desde el comienzo: la estructura binaria de dos momentos diferentes y sucesivos - reproducida en el juego entre "después" y "ahora" del verso 13- y la anticipación de lo bello para dejar al final el descubrimiento de la realidad, plasmado en el verso de cierre, con el "Amor" en el primer hemistiquio y el "veneno", ya anunciado antes por la mención de la "sierpe", entenebreciendo las ilusiones y sellando el proceso con el símbolo del irreversible y definitivo desengaño.

\section{BIBLIOGRAFÍA CITADA}

ALONSO, DÁmASO. 1955. Estudios y ensayos gongorinos. Madrid: Gredos.

CIPlijausKaItÉ, BIRUTÉ (ed.). 1969. Góngora, Sonetos completos. Madrid: Castalia.

DARST, D. H. 1985. Imitatio (Polémica sobre la imitación en el Siglo de Oro). Madrid: Orígenes.

DodDIS MiRANDA, A. 1961. "Notas a un soneto de Góngora". Anales de la Universidad de Chile CXIX, 124: 54-63.

EsPINOSA, PEDRO. 1975. Poesías completas, ed. de F. López Estrada. Madrid: Espasa Calpe. 
García Galiano, ANTONIO. 1992. La imitación poética en el Renacimiento. Kassel: Reichenberger.

GATES, E. J. 1933. The Metaphors of Luis de Góngora. Philadelphia.

- 1935. "Góngora's Use of Proverbs". Hispania XVIII, 1: 50.

Gross, NATHAN. 1962. "Invention in an Imited Sonnet by Góngora". Modern Language Notes 77: 182-187.

Lirici 1968. 1968. Lirici del Cinquecento. Turín: UTET.

Millé, J. (ed.). 1972. Luis de Góngora, Obras completas. Madrid: Aguilar.

ROSSI, GIUSEPPE C. 1961. "Rileggendo un soneto di Góngora (e uno del Tasso)". Revista de Filología Española XIIV: 425-433.

UlIVI, F. 1959. L'imitazione nella poesia del Rinascimento. Milán: Marzorati. 